\title{
Reliability Design of Mechanical Systems Such as Compressor Subjected to Repetitive Stresses ${ }^{\dagger}$
}

\author{
Seongwoo Woo ${ }^{1, *(1)}$ and Dennis L. O'Neal ${ }^{2}$ (D) \\ 1 Department of Mechanical Engineering, College of Electrical and Mechanical Engineering, \\ Addis Ababa Science and Technology University, Addis Ababa P.O. Box 16417, Ethiopia \\ 2 Department of Mechanical Engineering, School of Engineering and Computer Science, Baylor University, \\ Waco, TX 76798-7356, USA; dennis_oneal@baylor.edu \\ * Correspondence: twinwoo@yahoo.com; Tel.: +251-90-047-6711 \\ + Presented at the First International Electronic Conference on Metallurgy and Metals (IEC2M 2021).
}

\section{check for}

updates

Citation: Woo, S.; O'Neal, D.L. Reliability Design of Mechanical Systems Such as Compressor Subjected to Repetitive Stresses. Metals 2021, 11, 1261. https:// doi.org/10.3390/met11081261

\section{Academic Editors: João}

Pedro Oliveira, Belén Díaz Fernández, Leszek Adam Dobrzański,

Jae-chun Lee, Alex Lanzutti, Eric D. van Hullebusch and Filippo Berto

Received: 2 July 2021

Accepted: 6 August 2021

Published: 10 August 2021

Publisher's Note: MDPI stays neutral with regard to jurisdictional claims in published maps and institutional affiliations.

Copyright: (c) 2021 by the authors. Licensee MDPI, Basel, Switzerland. This article is an open access article distributed under the terms and conditions of the Creative Commons Attribution (CC BY) license (https:/ / creativecommons.org/licenses/by/ $4.0 /)$.

\begin{abstract}
This study demonstrates the use of parametric accelerated life testing (ALT) as a way to recognize design defects in mechanical products in creating a reliable quantitative (RQ) specification. It covers: (1) a system BX lifetime that $\mathrm{X} \%$ of a product population fails, created on the parametric ALT scheme, (2) fatigue and redesign, (3) adapted ALTs with design alternations, and (4) an evaluation of whether the system design(s) acquires the objective BX lifetime. A life-stress model and a sample size formulation, therefore, are suggested. A refrigerator compressor is used to demonstrate this method. Compressors subjected to repetitive impact loading were failing in the field. To analyze the pressure loading of the compressor and carry out parametric ALT, a mass/energy balance on the vapor-compression cycle was examined. At the first ALT, the compressor failed due to a cracked or fractured suction reed valve made of Sandvik $20 \mathrm{C}$ carbon steel ( $1 \mathrm{wt} \% \mathrm{C}, 0.25 \mathrm{wt} \% \mathrm{Si}, 0.45 \mathrm{wt} \% \mathrm{Mn}$ ). The failure modes of the suction reed valves were similar to those valves returned from the field. The fatigue failure of the suction reed valves came from an overlap between the suction reed valve and the valve plate in combination with the repeated pressure loading. The problematic design was modified by the trespan dimensions, tumbling process, a ball peening, and brushing process for the valve plate. At the second ALT, the compressor locked due to the intrusion between the crankshaft and thrust washer. The corrective action plan specified to perform the heat treatment to the exterior of the crankshaft made of cast iron $(0.45 \mathrm{wt} \% \mathrm{C}, 0.25 \mathrm{wt} \% \mathrm{Si}, 0.8 \mathrm{wt} \% \mathrm{Mn}, 0.03 \mathrm{wt} \% \mathrm{P})$. After these design modifications, there were no troubles during the third ALT. The lifetime of the compressor was secured to have a B1 life of 10 years.
\end{abstract}

Keywords: mechanical product; fatigue; design defects; parametric ALT; compressor

\section{Introduction}

Because of demands in the global market, refrigerators must be designed to have low energy usage and reliability. For those aimed functions, the compressor in the refrigerator often needs to be redesigned to enhance its comprehensive energy efficiency on a yearly basis. It involves recently designed features for the system, which should be rapidly brought to the end-users. With insufficient testing or no assumption of how the new attributes may be utilized, their launching may increase product failures in the marketplace and negatively influence the manufacturer's brand name. These attached features for the product should be totally assessed in the design phase before being released into the marketplace. Therefore, reliability quantitative (RQ) specifications utilizing an established system of method should be presented [1,2].

A compressor is designed to increase the refrigerant pressure in a refrigeration cycle by several mechanical compression mechanisms. One of the key components of the compressor is the crankshaft that converts the rotational motion into reciprocating motion by a crank mechanism. A compressor is subjected to repeated stresses due to internal 
pressure loadings over the course of its lifetime. New rotary compressors introduced in 1987 in refrigerators were experiencing large recalls due to the locking of the compressor in the field [3]. Oil metal sludge formed during normal refrigeration operations was separating from the sintering crankshaft and plugging the capillary tubes, which forced the refrigerator to no longer function. To stop a compressor recall, any flawed components needed to be identified and altered using testing methodology such as parametric ALT, which can produce reliability quantitative (RQ) specifications before the system launches.

The procedures of robust design, such as the Taguchi approach $[4,5]$ and design of experiments (DOE) [6], were developed to help identify the most advantageous designs for products. Especially, Taguchi's method employs design parameters to put it in the right location where "noise" parameters do not have any effect on the output. As a result, the right designs of mechanical products can be selected. However, without identifying failure mechanisms such as fatigue, this methodology can only pursue system optimization. If there is a design fault, the product may fail during its lifetime as loads are exerted on it. Many parameters must be considered to identify an optimal design of a mechanical structure. However, the large number of parameters may require huge computations unless some options are neglected to reduce computational requirements.

Material faults, such as extremely small voids and contacts when subjected to repeated loads, may begin to fail because of fatigue. Fatigue is the chief source of destruction in metallic elements, explaining roughly $80-95 \%$ of all constructional failures [7-9]. Fatigue in ductile metals appears itself in the shape of cracks that grow in stress accumulation, such as holes, grooves, etc. Those failures can affect the reliability of mechanical systems such as moving automobiles, airplane wings, marine ships, turbo engines, and atomic reactors. The fatigue procedure covers three fluctuating stress/time modes: (1) symmetrical about zero stresses, (2) asymmetrical about zero stresses, and (3) random stress cycles. The fatigue may also rely on the parameters such as the cyclic stress amplitude, mean stress or stress ratio, $\mathrm{R}\left(=\sigma_{\min } / \sigma_{\max }\right)$, which can be defined as $\mathrm{s}$ the proportion of the minimum cyclic stress to the maximum cyclic stress [10]. In other words, in periodical shapes, the peaks on both the maximum (high side) and the minimum (low side) are crucial. When employing an elevated load which can be stated as an accelerated factor $(A F)$, accelerated life testing (ALT) can be examined to discover the design defects such as stress raiser in the structure.

The ALT combined on the reliability block diagram was investigated as another method [11]. It included a test plan for the system, identifying failure mechanics such as fatigue, and using sample size equation, accelerated loads, etc. Elsayed [12] categorized statistical, physics/statistics, and physics/experimental-established prototypes for examination. Meeker [13] suggested numerous practical ways to organize an ALT. Carrying out an ALT $[14,15]$ necessitates numerous notions such as the BX life for the system test scheme, a simplified life-stress description, sample size formulation, and fracture mechanics [16-18] because failure may happen suddenly from the fragile components in a product. Contemporary test techniques [19-26] might be hard to replicate the design flaws of components in a multi-module system because those procedures evaluate insufficient component samples and do not identify the fatigue(s) which actually occur in the marketplace.

To attain the sound design of a mechanical product, designers have employed traditional techniques such as fracture mechanics and strength of materials [27]. As quantum as one of the branches of mechanics has developed, engineers identified which failures came from micro-void coalescence (MVC) and discovered many metallic alloys or some engineering plastics. To find the fatigue source of a mechanical product, a life-stress model can be incorporated with conventional design methods and relevant techniques to help identify the failure of electronic parts due to present material flaws or small cracks when the parts are subjected to (mechanical) stresses. Finite element methods (FEMs) may not identify the source of failure [28].

To show the effectiveness for identifying and altering the design defects of a mechanical product, this research proposes using a parametric ALT as a systematic reliability method that can create the RQ specifications-mission cycles. It covers: (1) a system BX 
lifetime created on the ALT scheme, (2) a load examination for ALT, (3) tailored ALTs with the alterations, and (4) an estimation of whether the product design(s) accomplishes the objective BX lifetime. The derivation of the sample size equation, time-to-failure, and BX lifetime is provided. To confirm ALT results in real life and compare the current design with previous one, it would then be necessary to monitor the introduction of the new design in the market to ensure it reached the targeted lifetime and failure rate. A newly designed compressor in a domestic refrigerator subjected to repeated pressure impact loading is used as an example of this methodology.

\section{Parametric ALT for Mechanical Product}

\subsection{BX Lifetime of a Mechanical System}

To perform an ALT, the BX life, $L_{B}$, is needed as a measure of the product lifetime. It can identify the accumulative failure rate and meet the market needs for reliability requirements of the product. $\mathrm{BX}$ life is the elapsed time for which $\mathrm{X} \%$ of a population of a product fails. Thus, a "BX life Y years" is a way for expressing the system lifetime. For example, if a system lifetime has a B20 life of 10 years, then $20 \%$ of the population will fail during 10 years of operation. On the other hand, the mean time to failure (MTTF) - the B60 lifetime-is not acceptable for identifying the system lifetime because it takes too long for $60 \%$ of the population of the product to fail. The BX life is a more suitable measure of a lifetime.

In a mechanical product, movements of power for acquiring mechanical advantages are utilized in functions that require forces and movement by accommodating certain system mechanisms. As products are subjected to repeated stresses, they should have a proper lifetime for those stresses. For instance, to maintain the freshness of food products, a refrigerator is designed to provide cooled air from a heat exchanger such as an evaporator to the refrigerator (or freezer) sections. The refrigerator is made up of different modules: the cabinet, door, internal fixtures (shelves and drawers), controls and instruments, electric motor, compressor, heat exchangers (evaporator and condenser), water supply device, and numerous dissimilar parts. A refrigerator has approximately 2000 components (Figure 1a). A target of the refrigerator's lifetime is set to have a B20 life 10 years. If a refrigerator consists of 20 units and each unit has 100 components, the lifetime of each unit should be designed to have a B1 life 10 years. The required system lifetime of a refrigerator relies on the many components, including the compressor. If the compressor has design faults, it impacts the potential life of the refrigerator (Figure 1b).

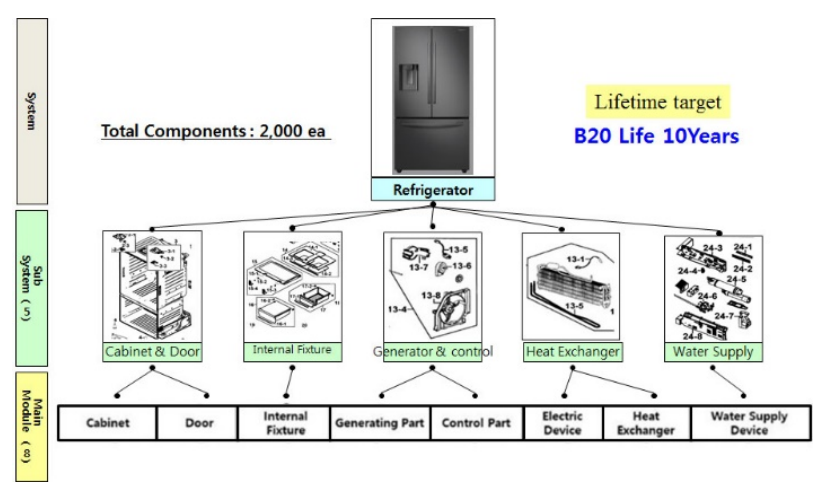

(a)

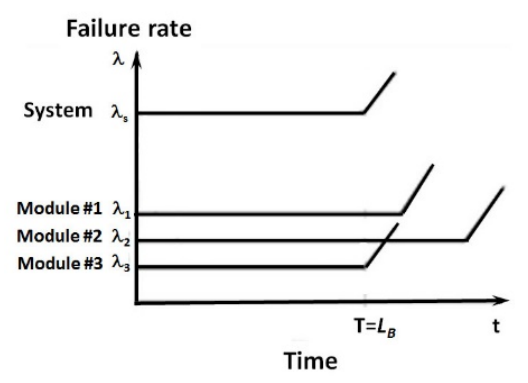

(b)

Figure 1. Product lifetime decided by newly designed module (a) categorization of multi-module refrigerator; (b) product lifetime $L_{B}$ and failure rate $\lambda_{\mathrm{s}}$. 


\subsection{Placing an Entire Parametric ALT Scheme}

For a stated period of time, the reliability for a compressor can be explained as the capacity needed to continue performing the intended function under specified environmental/operational conditions [29]. It can be explained using the traditional "bathtub curve", which is composed of three regions, as seen in the top curve of Figure 2. In the first region, during the early product life, there is some reduction in the failure rate. In the second region, during its middle life, there is a relatively constant failure rate. In the third region, there is a growing failure rate until the final life of the product. If a product follows this classic pattern, it might not be successful in the marketplace due to the tall initial failure rates and the relatively short lifetime of the product due to built-in design flaws. Companies need to upgrade the system design by setting its reliability targets to (1) remove premature failures, (2) reduce random failures over the product lifetime, and (3) enlarge product lifetime. As the design of a mechanical product improves, its failure rate in the field decreases, and the system lifetime can be increased. For such situations, the traditional bathtub curve might be altered to the bottom curve in Figure 2, where failure rates are low throughout the life of the product except toward the end of its expected life.

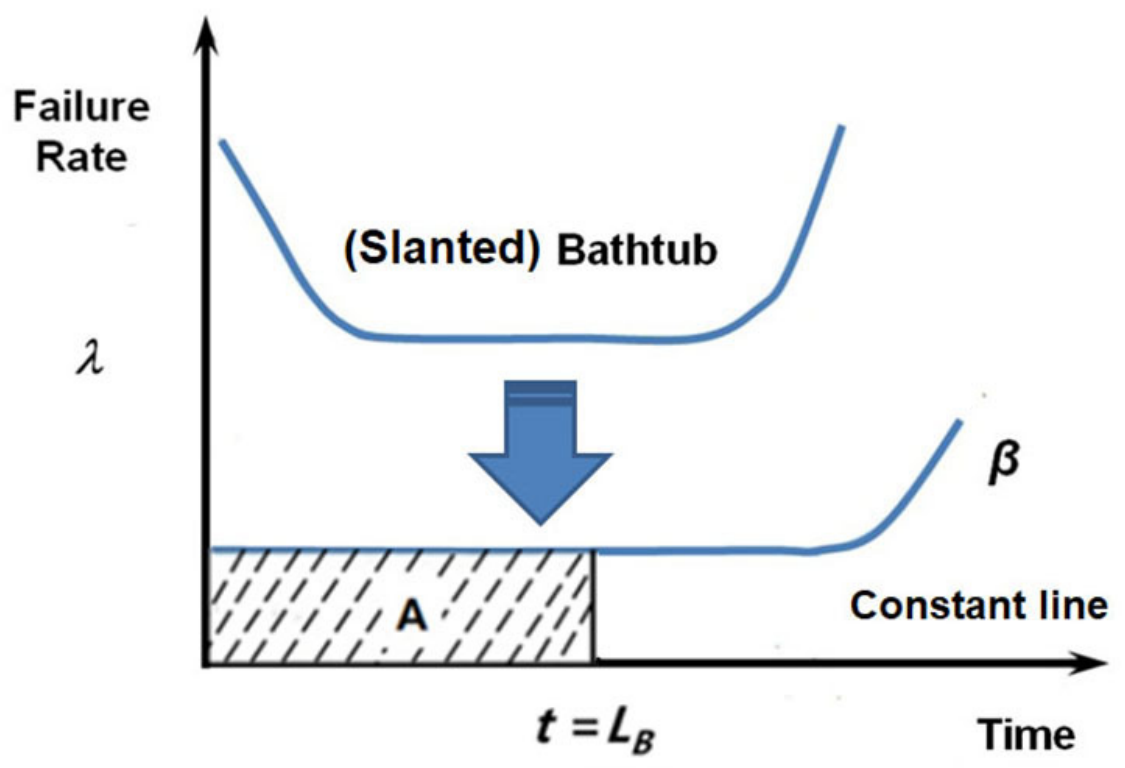

Figure 2. Bathtub curve and straight line.

The failure rate on the bathtub in Figure 2 can be stated as

$$
\lambda=\frac{f}{R}=\frac{d F / d t}{R}=\frac{(1-R)^{\prime}}{R}=\frac{-R^{\prime}}{R}
$$

where $\lambda$ is the failure rate, $f$ is the failure density function, $R$ is the reliability, and $F$ is the unreliability of the product.

If Equation (1) is integrated over time, the $X \%$ cumulative failure $F\left(L_{B}\right)$ at $B X$ life, $L_{B}$, can be obtained:

$$
\int \lambda d t=-\ln R
$$

That is, it can be stated as:

$$
A=\langle\lambda\rangle \cdot L_{B}=\int_{0}^{L_{B}} \lambda(t) \cdot d t=-\ln R\left(L_{B}\right)=-\ln (1-F) \cong F\left(L_{B}\right)(=X)
$$


As a product has a lower failure rate of the straight line that follows an exponential distribution, the reliability of a mechanical system could be stated as the product lifetime $L_{B}$ and failure rate $\lambda$ :

$$
R\left(L_{B}\right)=1-F\left(L_{B}\right)=e^{-\lambda L_{B}} \cong 1-\lambda L_{B}
$$

This relationship is suitable below about $20 \%$ of the cumulative failure [30]. After targeting the lifetime, $L_{B}$, and failure rate, $\lambda$, the mechanical product can be redesigned by identifying the troublesome structures and altering them by a parametric ALT (Figure 3).

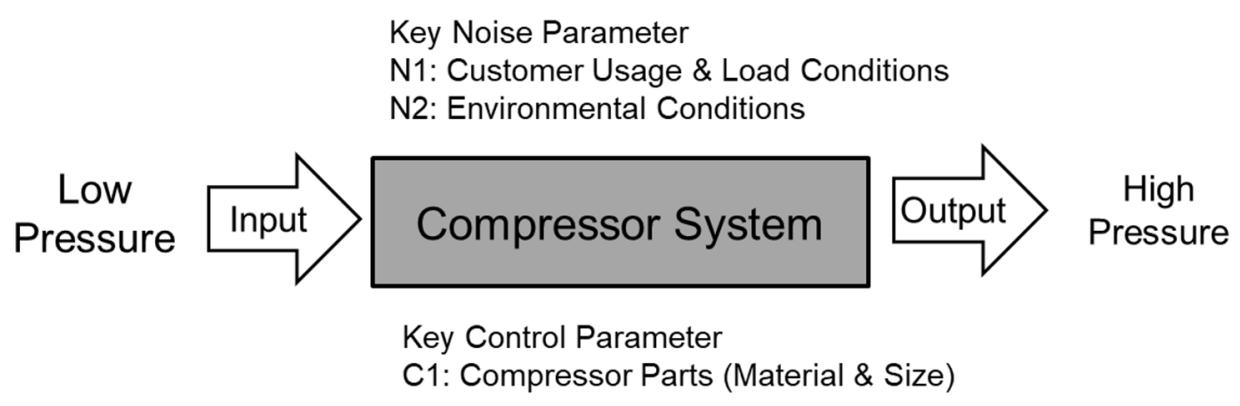

Figure 3. Parameter diagram of compressor (example).

To target the lifetime of a mechanical system through a parametric ALT, there are three possible system modules: (1) modified independent units, (2) newly designed independent units, and (3) similar independent units to the earlier design base on request in the field. The modified compressor in the refrigerator inspected here is used as a case study. It was originally redesigned to enhance its energy efficiency and make the refrigerator more competitive in the marketplace. However, the redesigned compressor had design faults that needed to be altered because of failures in the field.

The altered independent units $\mathrm{D}$ from the field data manifested in Table 1 had a failure rate of $0.31 \%$ per year and a B1 life of 3.2 years. The lifetime of compressors, based on data from the field, indicated they had an expected B1 life of 1.6 years because they had a failure rate of $0.62 \%$ per year. To satisfy consumer demands, a new lifetime target for the mechanical system such as compressor was put to have a B1 life of 10 years with 0.1 percent per year.

Table 1. Whole ALT scheme of mechanical modules in a refrigerator.

\begin{tabular}{|c|c|c|c|c|c|c|c|c|}
\hline \multirow{3}{*}{$\begin{array}{c}\text { Modules } \\
\text { A }\end{array}$} & \multicolumn{2}{|c|}{ Field Data } & \multicolumn{4}{|c|}{ Expected Reliability } & \multicolumn{2}{|c|}{ Aimed Reliability } \\
\hline & \multirow{2}{*}{$\begin{array}{c}\begin{array}{c}\text { Failure Rate per } \\
\text { Year, \%/Year }\end{array} \\
0.35\end{array}$} & \multirow{2}{*}{$\begin{array}{c}\begin{array}{c}\text { BX Life, } \\
\text { Year }\end{array} \\
2.9\end{array}$} & \multicolumn{3}{|c|}{ Failure Rate per Year, \%/Year } & \multirow{2}{*}{$\begin{array}{c}\begin{array}{c}\text { BX Life, } \\
\text { Year }\end{array} \\
2.9\end{array}$} & \multirow{2}{*}{$\begin{array}{c}\begin{array}{c}\text { Failure Rate per } \\
\text { Year, \%/Year }\end{array} \\
0.10\end{array}$} & \multirow{2}{*}{$\begin{array}{c}\begin{array}{c}\text { BX Life, } \\
\text { Year }\end{array} \\
10(\mathrm{BX}=1.0)\end{array}$} \\
\hline & & & Similar & $\times 1$ & 0.35 & & & \\
\hline $\mathrm{B}$ & 0.24 & 4.2 & New & $\times 5$ & 1.20 & 0.83 & 0.10 & $10(\mathrm{BX}=1.0)$ \\
\hline $\mathrm{C}$ & 0.30 & 3.3 & Similar & $\times 1$ & 0.30 & 3.33 & 0.10 & $10(\mathrm{BX}=1.0)$ \\
\hline $\mathrm{D}$ & 0.31 & 3.2 & Altered & $\times 2$ & 0.62 & 1.61 & 0.10 & $10(\mathrm{BX}=1.0)$ \\
\hline $\mathrm{E}$ & 0.15 & 6.7 & Altered & $\times 2$ & 0.30 & 3.33 & 0.10 & $10(\mathrm{BX}=1.0)$ \\
\hline Others & 0.50 & 10.0 & Similar & $\times 1$ & 0.50 & 10.0 & 0.50 & $10(\mathrm{BX}=5.0)$ \\
\hline Product & 1.9 & 2.9 & - & - & 3.27 & 0.83 & 1.00 & $10(\mathrm{BX}=10)$ \\
\hline
\end{tabular}

\subsection{Failure Mechanics and Parametric ALT for Redesign}

As mentioned in Section 2.1, mechanical products usually transfer power (or energy) from one position to another by adapting proper mechanisms. For example, the compressor in a refrigerator, by utilizing the vapor-compression cycle, increases the refrigerant pressure using a crankshaft mechanism. It is subjected to repeated stresses because of pressure loading. If there is a design defect in the structure that creates an insufficient strength (or stiffness) when the loads are applied, the mechanical product may abruptly collapse before its expected lifetime. 
Metal fatigue is the familiar word that can be used to express the unanticipated failure of product components that develop fractures in their lifetime. It is connected to the number of stress cycles experienced by a component and the amount of stress exerted on the component. The S-N curve shows that an infinite life is possible for a metal component if the stresses in the component remain below a clearly defined lower stress boundary. Metal fatigue grows if there is a stress raiser such as notches in a component. An engineer should identify these design flaws using appropriate analysis or testing. There is also a correlation between a metal component's ultimate tensile strength and hardness and its capability to endure fatigue loads. The loftier the tensile strength and hardness, the more probably it will fatigue if subjected to higher fluctuating loads.

Fatigue failure due to design defects can be characterized by two components: (1) the stress due to loads on the constructional system and (2) the type of materials (or shape) utilized in the structure. In recognizing the product failure by a parametric ALT, an engineer could optimally design parts with good forms and proper materials. The system could bear repeated loads over its lifetime so that it could fulfill the reliability target (Figure 4).

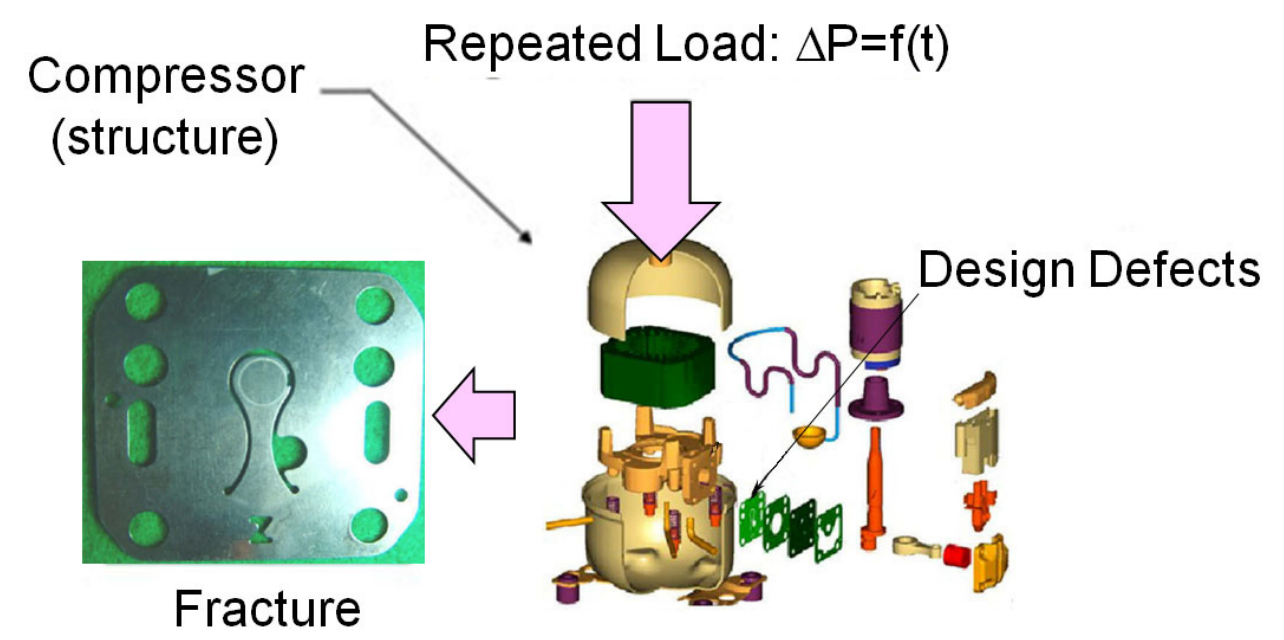

Figure 4. Fatigue failure on the structure created by repetitive loading and design flaws.

The main problem for reliability testing is to determine how quickly the potential failure mode can be identified. To complete it, it is necessary to successfully formulate a simplified failure description and determine the correct coefficients for the model. A lifestress (LS) model can be developed, which incorporates stresses and reaction parameters. This model can explain various mechanical failures such as fatigue in the structure. Fatigue failures can occur not due to stresses in a perfect part but rather due to the present defects or very small cracks on the exterior of a component.

As fatigue originates from material flaws created on a macro or microscopic scale level, the life-stress model can be defined from such a point of view. For instance, we can utilize the procedures for solid-state diffusion of impurities in silicon, which is commonly used as semi-conduct material, such as in the following procedure: electro-migration-induced voiding, growth of chloride ions, and catching of electrons or holes. As an electric magnetomotive force, $\xi$, is exerted, the impurities such as voids in materials, created by electronic movement, are effortlessly migrated because the barriers of junction energy are dropped and distorted/phase-shifted. For solid-state diffusion of impurities in silicon, the junction equation J might be expressed as follows [31,32] (Figure 5): 


$$
\begin{aligned}
& J=[a C(x-a)] \cdot \exp \left[-\frac{q}{k T}\left(w-\frac{1}{2} a \xi\right)\right] \cdot v \\
& {[\text { Density } / \text { Area }] \cdot[\text { Jump Probability }] \cdot[\text { Jump Frequency }]} \\
& =-\left[a^{2} v e^{-q w / k T}\right] \cdot \cosh \frac{q a \xi}{2 k T} \frac{\partial C}{\partial x}+\left[2 a v e^{-q w / k T}\right] C \sinh \frac{q a \xi}{2 k T} \\
& =\Phi(x, t, T) \sinh (a \xi) \exp \left(-\frac{Q}{k T}\right) \\
& =B \sinh (a \xi) \exp \left(-\frac{Q}{k T}\right)
\end{aligned}
$$

where $C$ is the concentration, $q$ is the magnitude of electric charge, $v$ is the frequency, $\Phi()$ is a constant, $B$ is a constant, $a$ is the interval between atoms, $\xi$ is the applied field, $k$ is the Boltzmann's constant, $T$ is the temperature, and $Q$ is the energy.

Electric magneto-motive force, $\xi$, is Applied

Initial state

Potential, J

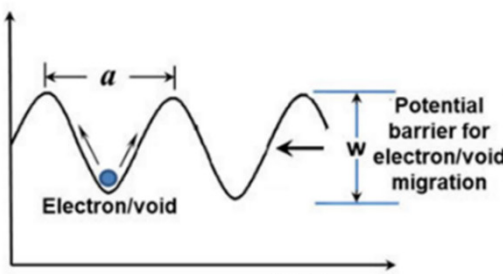

Distance

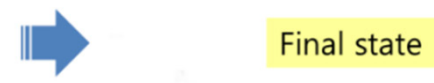

Potential, J

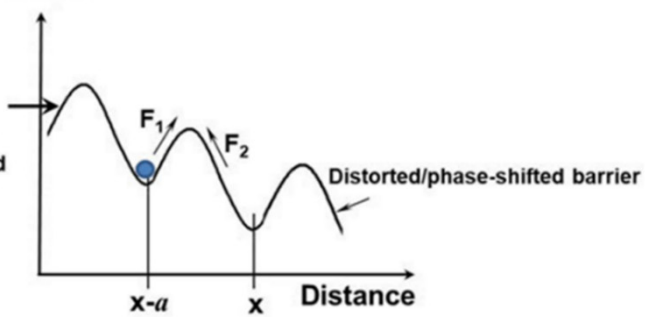

Figure 5. Potential exchange in material such as silicon as electrical field is exerted.

The reaction process, which depends on speed, could be stated as

$$
\begin{gathered}
K=K^{+}-K^{-}=a \frac{k T}{h} e^{-\frac{\Delta E-a S}{k T}}-a \frac{k T}{h} e^{-\frac{\Delta E+a S}{k T}} \\
=a \frac{k T}{h} e^{-\frac{\Delta E}{k T} \sinh \left(\frac{a S}{k T}\right)=B \sinh (a S) \exp \left(-\frac{\Delta E}{k T}\right)}
\end{gathered}
$$

where $K$ is the reaction rate, $S$ is the (chemical) effect, $T$ is the temperature, $k$ is Boltzmann's constant, $E$ is the (activation) energy, and $\Delta$ is the difference.

The reaction rate $K$ from Equations (5) and (6) could be simplified as

$$
K=B \sinh (a S) \exp \left(-\frac{E_{a}}{k T}\right)
$$

If Equation (7) takes an inverse function, the life-stress (LS) model might be stated as

$$
T F=A[\sinh (a S)]^{-1} \exp \left(\frac{E_{a}}{k T}\right)
$$

The sine hyperbolic expression $[\sinh (a S)]^{-1}$ in Equation (8) can be stated as (Figure 6):

1. $(S)^{-1}$ at first has a little linear result;

2. $(S)^{-n}$ has what is regarded as a medium result;

3. $\left(e^{a S}\right)^{-1}$ at end is large. 


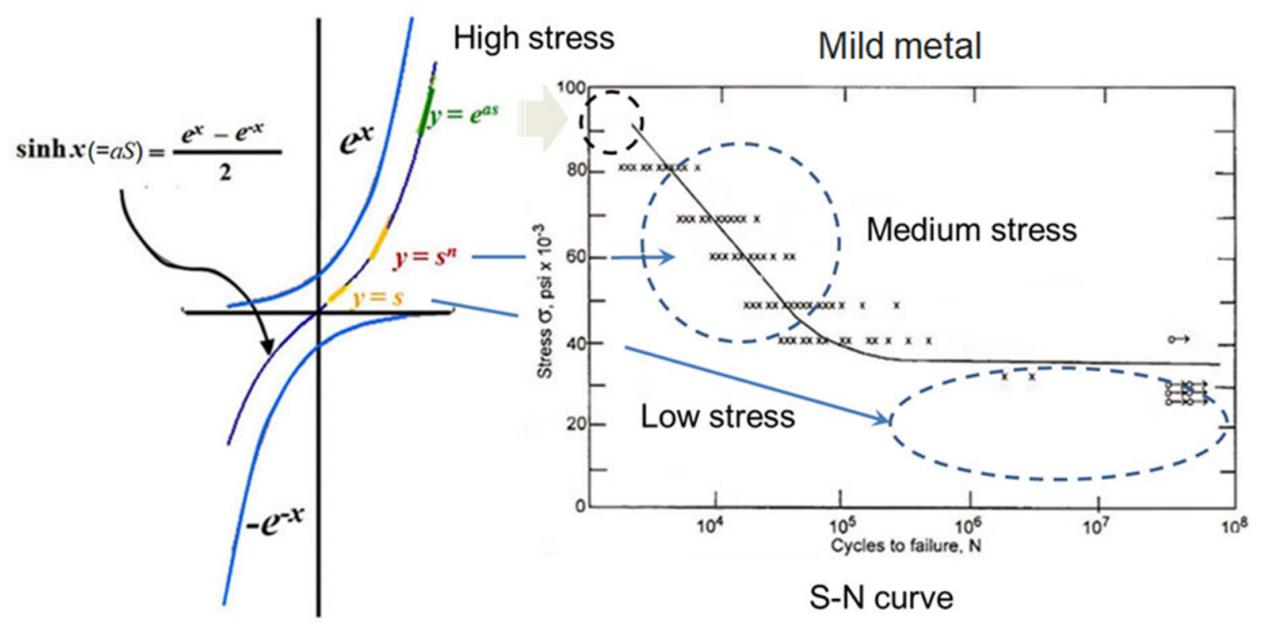

Figure 6. Hyperbolic sine stress term versus S-N curve from a standpoint of stress range.

An ALT is usually conducted in the medium scope, and Equation (5) might be stated as

$$
T F=A(S)^{-n} \exp \left(\frac{E_{a}}{k T}\right)
$$

Because the stress level in a mechanical system may be hard to be computed during ALT, Equation (9) must be restated. As the power is stated as the product of flows and effort, stresses may originate from effort in a multi-port product (Table 2) [33].

Table 2. Power concept in a multi-port product expressed as effort and flow.

\begin{tabular}{ccc}
\hline System & Effort, $\boldsymbol{e}(t)$ & Flow, $f(t)$ \\
\hline Translation system & Force, $F(t)$ & Velocity, $V(t)$ \\
Rotation system & Torque, $\tau(t)$ & Angular velocity, $\omega(t)$ \\
Pump, compressor & Pressure difference, $\Delta P(t)$ & Volume flow rate, $Q(t)$ \\
Electric system & Voltage, $V(t)$ & Current, $i(t)$ \\
Magnetic & Magneto-motive force, $e_{m}$ & Magnetic flux,$\varphi$ \\
\hline
\end{tabular}

Stress is a material quantity that specifies the inner forces which adjoining particles of a continuum material exert on each other. For a mechanical system, because stress originates from effort, Equation (9) might be stated as

$$
T F=A(S)^{-n} \exp \left(\frac{E_{a}}{k T}\right)=B(e)^{-\lambda} \exp \left(\frac{E_{a}}{k T}\right)
$$

where $A$ and $B$ are constants.

To obtain the acceleration factor $(A F)$, which can mostly affect the evaluation of fatigue strength in a product, $A F$ might be stated as the ratio between the proper elevated stress levels and normal working conditions. $A F$ might be modified to integrate the effort notion:

$$
A F=\left(\frac{S_{1}}{S_{0}}\right)^{n}\left[\frac{E_{a}}{k}\left(\frac{1}{T_{0}}-\frac{1}{T_{1}}\right)\right]=\left(\frac{e_{1}}{e_{0}}\right)^{\lambda}\left[\frac{E_{a}}{k}\left(\frac{1}{T_{0}}-\frac{1}{T_{1}}\right)\right]
$$

\subsection{Parametric ALT for Mechanical Systems}

To acquire the mission cycle of parametric ALTs from the targeted BX lifetime on the test plan in Table 1, the sample size equation combined with the $A F$ should be attained [1] (see Appendix A). 


$$
n \geq(r+1) \times \frac{1}{x} \times\left(\frac{L_{B}^{*}}{A F \cdot h_{a}}\right)^{\beta}+r
$$

If the lifetime of a mechanical system, such as the domestic compressor, is targeted to have a B1 life of 10 years, the mission cycles might be acquired for an assigned set of samples subjected to (impact) loading. In parametric ALTs, the design defects of the new product might be identified to help satisfy the lifetime target.

\subsection{Case Study_Design of a Recently Designed Domestic Compressor in a Refrigerator}

Operating with unspecified consumer usage conditions, the suction reed valves in compressors used in the field were unsuccessful. The fractured suction reed valve caused the domestic compressor to lock and quit functioning. As the primary purpose of the refrigerator, including the compressor, was lost, consumers would solicit to have the product exchanged. To address the problem, it was crucial to reproduce the failure mode(s) of the compressor in simulated conditions in a room or building equipped for engineering experiments. Seemingly, the troublesome compressors that came from the field had two evident design flaws: (1) the suction reed valve had a quantity of overlap with the valve plate, and (2) the valve plate had a sharp edge. As the suction reed valve impacted the valve plate, it would fail before its expected lifetime (Figure 7).

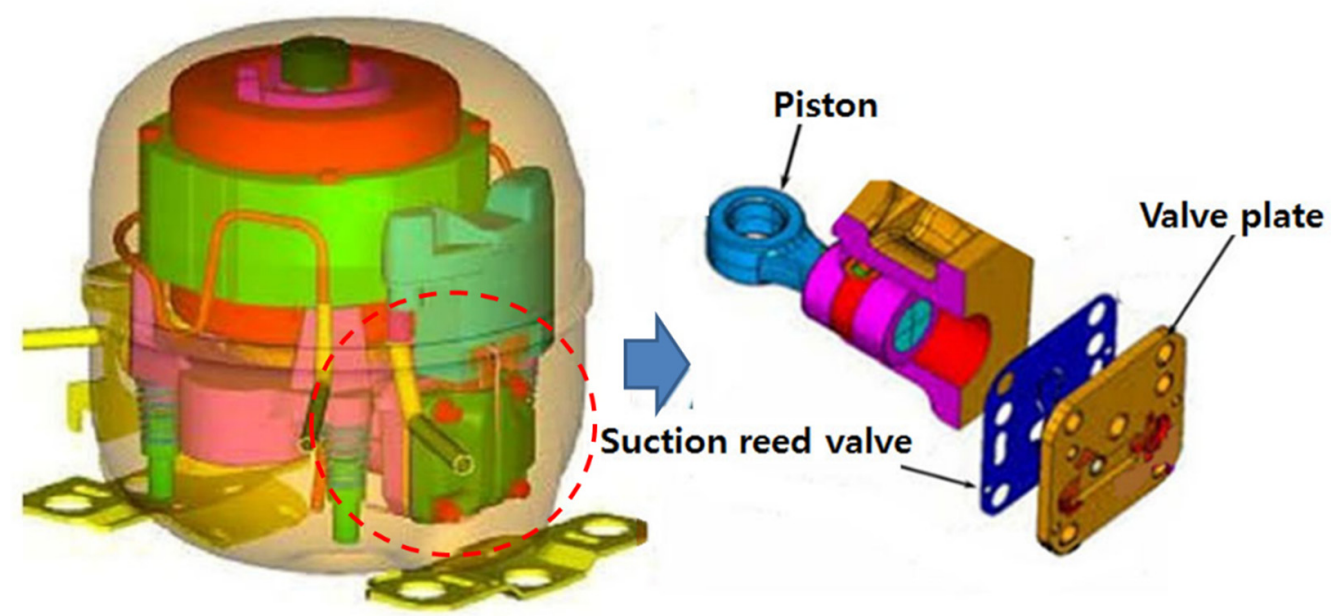

(a)

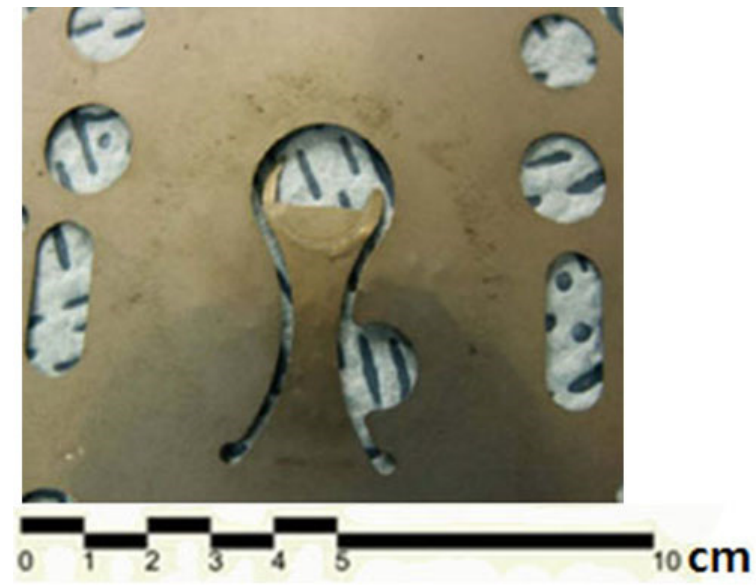

(b)

Figure 7. Failed suction reed valve: (a) suction reed valve and valve plate in a compressor. (b) Fractured suction reed valve from the marketplace or parametric ALT. 
To chill the stored products in a refrigerator, the refrigerator supplies cooled air from the evaporator heat exchanger to the freezer (or refrigerator) departments. The vaporcompression cycle in a refrigerator covers a compressor, condenser, capillary tube, and evaporator. Electrical energy in the compressor motor is converted to work energy in the compressor that is used to elevate the refrigerant pressure. With refrigerant flowing in the system, heat energy absorbed by the evaporator is moved to the condenser, where it is rejected to the surrounding air. A capillary tube manages the refrigerant flow and controls the flow of refrigerant from the high-pressure refrigerant in the condenser to the lowpressure refrigerant in the evaporator. In an ideal vapor-compression refrigeration cycle, the refrigerant enters the compressor as a saturated vapor (Processes 1-2) and is cooled to the saturated liquid state in the condenser (Processes 2-3). It then drops in pressure as it goes through the expansion device to the lower pressure evaporator (Processes 3-4). In the evaporator, the refrigerant is vaporized as it absorbs heat from the refrigerated space (Processes 4-1) (Figure 8).

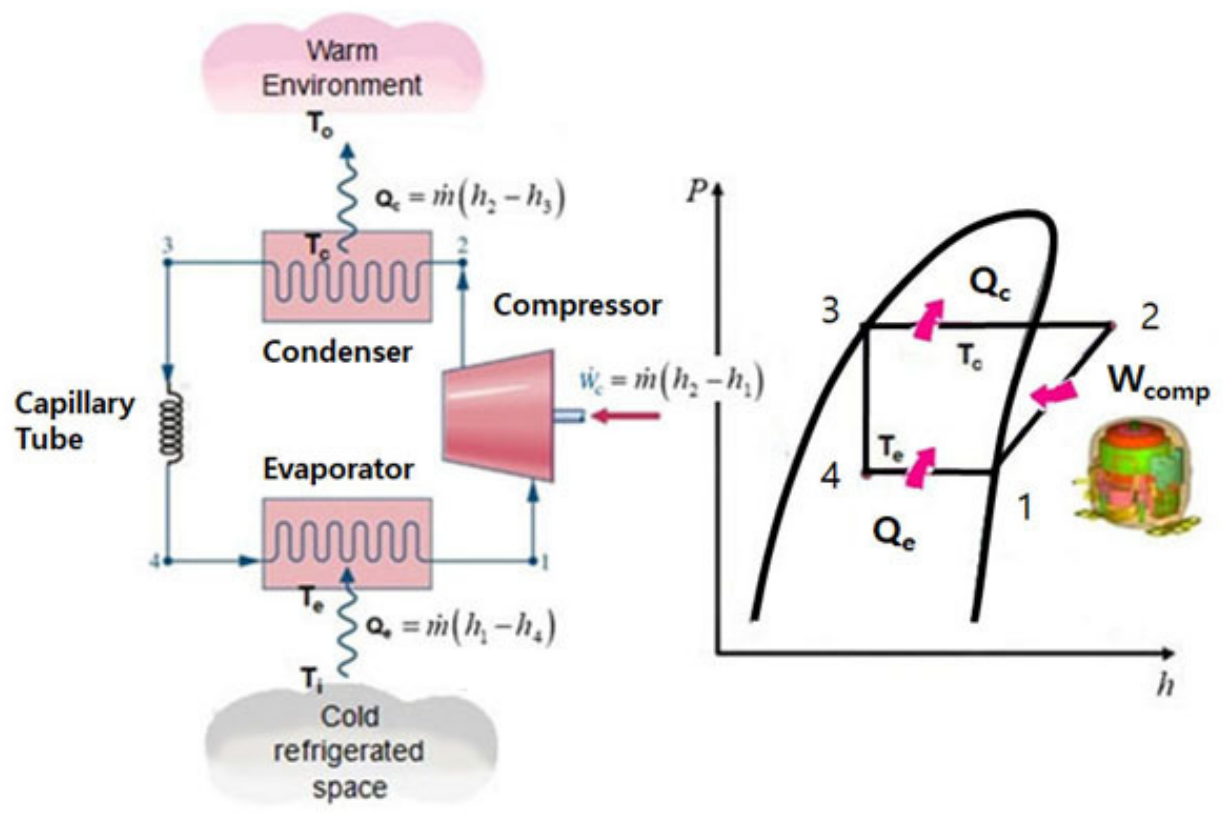

(a)

(b)

Figure 8. A domestic compressor in the refrigeration cycle: (a) vapor-compression refrigerator cycle, (b) $\mathrm{P}$ h diagram.

During normal operation, refrigerator compressors are subjected to repetitive stresses due to pressure loads differences in the compressor. If there is a design fault in a component, such as an insufficiency of strength, when the loads are applied in the compressor, the component may abruptly fail and not meet its expected lifetime. By identifying the system failure by a parametric ALT, an engineer can select proper material and redesign the component using the best or most favorable way so the compressor can support repeated loads and its lifetime can be increased. It is necessary to analyze the pressure loads in the compressor.

In a representative refrigeration cycle, to assess its design, it was required to determine both the condensing temperature, $T_{c}$, and evaporating temperature, $T_{e}$. The mass flow rate of refrigerant in a compressor can be modeled as

$$
\dot{m}=P D \times \frac{\eta_{v}}{v_{s u c}}
$$

where $P D$ is the piston displacement, $\eta_{v}$ is the compressor's volumetric efficiency, and $v_{s u c}$ is the specific volume at compressor suction port. 
The mass flow rate of the refrigerant at the capillary tube can be modeled as [34].

$$
\dot{m}_{\text {cap }}=A\left[\frac{-\int_{P_{3}}^{P_{4}} \rho d P}{\frac{2}{D} f_{m} \Delta L+\ln \left(\frac{\rho_{3}}{\rho_{4}}\right)}\right]^{0.5}
$$

By conservation of mass, the mass flow rate can be stated as:

$$
\dot{m}=\dot{m}_{\text {cap }}
$$

The energy conservation at the condenser can be stated as

$$
Q_{c}=\dot{m}\left(h_{2}-h_{3}\right)=\left(T_{c}-T_{o}\right) / R_{c}
$$

The energy conservation at the evaporator can be stated as

$$
Q_{e}=\dot{m}\left(h_{1}-h_{4}\right)=\left(T_{i}-T_{e}\right) / R_{e}
$$

Using Equations (15) through (17), it is possible to obtain estimates of the mass flow rate, $\dot{m}$, evaporator temperature, $T_{e}$, and condenser temperature, $T_{c}$. Because the saturation pressure, $P_{\text {sat }}$, is a function of temperature, we can obtain the evaporator pressure, $P_{e}$ (or condenser pressure $P_{c}$ ).

$$
P_{e}=f\left(T_{e}\right) \text { or } P_{c}=f\left(T_{c}\right)
$$

Both the condensing pressure, $P_{c}$, and evaporating pressure, $P_{e}$, are important when examining the load on the compressor. These pressures depend on the environmental conditions, heat exchanger size, and customer usage conditions in the design stage.

During normal compressor operations, it will be subjected to repeated stresses due to the pressure differences between the suction and discharge. The internal stress of the compressor relies on the pressure difference between suction pressure, $P_{\text {suc }}$, and discharge pressure, $P_{\text {dis }}$.

$$
\Delta P=P_{\text {dis }}-P_{\text {suc }} \cong P_{c}-P_{e}
$$

Under accelerated conditions, the life-stress model (LS model) in Equation (10) can be stated as:

$$
T F=A(S)^{-n} \exp \left(\frac{E_{a}}{k T}\right)=A(\Delta P)^{-\lambda} \exp \left(\frac{E_{a}}{k T}\right)
$$

where $A$ is constant, $k$ is Boltzman's constant, $E_{a}$ is the activation energy, $T$ is the absolute temperature, $n$ is the quotient, and $\lambda$ is the cumulative damage exponent in PalmgrenMiner's rule.

So the acceleration factor $(A F)$ might be stated as:

$$
A F=\left(\frac{S_{1}}{S_{0}}\right)^{n}\left[\frac{E_{a}}{k}\left(\frac{1}{T_{0}}-\frac{1}{T_{1}}\right)\right]=\left(\frac{\Delta P_{1}}{\Delta P_{0}}\right)^{\lambda}\left[\frac{E_{a}}{k}\left(\frac{1}{T_{0}}-\frac{1}{T_{1}}\right)\right]
$$

where $S_{1}$ (or $P_{1}$ ) is mechanical stress (or pressure difference) under accelerated conditions, and $S_{0}$ (or $P_{0}$ ) is mechanical stress (or pressure difference) under representative conditions.

For a domestic compressor in a refrigerator, the typical operating conditions were for a customer span from $0{ }^{\circ} \mathrm{C}$ to $43{ }^{\circ} \mathrm{C}$ with a humidity fluctuating from $0 \%$ to $95 \%$. Vibration conditions presumed for working the compressor were subjected to 0.2 to $0.24 \mathrm{~g}$ of acceleration.

When the compressor operates, the suction reed valve opens to allow refrigerant to stream into the compressor. A compressor is expected to cycle on and off 22 cycles per day. A worst-case scenario was also duplicated with on and off of 98 cycles per day. Under the worst cases, the compressor working for 10 years may incur approximately 357,700 usage cycles. 
The compressor is usually made of (carbon, cast, stainless, alloy, etc.) steel. The allowable stresses are stated as a function of the yield stress $\left(F_{y}\right)$ or tensile stress $\left(F_{u}\right)$ of the structural material. For steel, the ranges of yield strength, $F_{y}$, and ultimate or tensile strength, $F_{u}$, ordinarily used are 248-345 MPa and 400-483 MPa, separately. Refrigerant $\mathrm{R} 134 \mathrm{a}$ is the refrigerant utilized in the refrigerant cycle. It uses synthetic refrigeration compressor oils that have a high Viscosity Index (VI). They have slight viscosity changes in relation to temperature changes. Therefore, the slope of the viscosity of a synthetic lubricant with a high VI is flatter with respect to temperature. The viscosity thus remains stable across a wide temperature usage range.

In the worst case, the pressure difference was $1.27 \mathrm{MPa}$, and the compressor dome temperature was $90^{\circ} \mathrm{C}$. For a parametric ALT, the pressure difference was elevated to be $2.94 \mathrm{MPa}$, and the compressor dome temperature was also elevated to be $120^{\circ} \mathrm{C}$, with an accumulative damage exponent, $\lambda$, of 2 . The total $A F$ computed from Equation (21) was 7.3 (Table 3).

Table 3. Compressor ALT conditions.

\begin{tabular}{|c|c|c|c|c|}
\hline \multicolumn{2}{|c|}{ System States } & \multirow{2}{*}{$\begin{array}{c}\text { Worst Case } \\
1.27\end{array}$} & \multirow{2}{*}{\begin{tabular}{r|} 
ALT \\
2.94
\end{tabular}} & \multirow{2}{*}{$\begin{array}{c}A F \\
5.36(1)\end{array}$} \\
\hline \multirow{3}{*}{ Pressure (MPa) } & High-side & & & \\
\hline & Low-side & 0.0 & 0.0 & - \\
\hline & $\Delta P$ & 1.27 & 2.94 & - \\
\hline Temperature $\left({ }^{\circ} \mathrm{C}\right)$ & Dome & 90 & 120 & 1.37 (2) \\
\hline Total $A F(=(1) \times(2))$ & - & - & - & 7.32 \\
\hline
\end{tabular}

The test cycles of the ALTs calculated from Equation (12) were 49,000 cycles for 100 samples if the shape parameter, $\beta$, was presumed to be 2.0. The parametric ALT was designed to reassure a lifetime target-B1 life of 10 years - with an approximate $60 \%$ level of confidence that it would fail less than once during 49,000 cycles. We also exerted the duty cycles of the pressure difference between suction pressure, $P_{s u c}$, and discharge pressure, $P_{\text {dis }}$.

To assess the design of the compressor, a straightforward refrigeration cycle was established. It contained a compressor, condenser, capillary tube, and evaporator. The temperature in the enveloped fiberglass package is controlled by two $60 \mathrm{~W}$ lamps and a fan. A thermal switch attached to the cover of the compressor managed a $51 \mathrm{~m}^{3} / \mathrm{h}$ axial fan. The test conditions and their borders were set up on the control board. As the test started, the high-side and low-side pressures were displayed on the pressure gauges or apparatus screen (Figure 9).
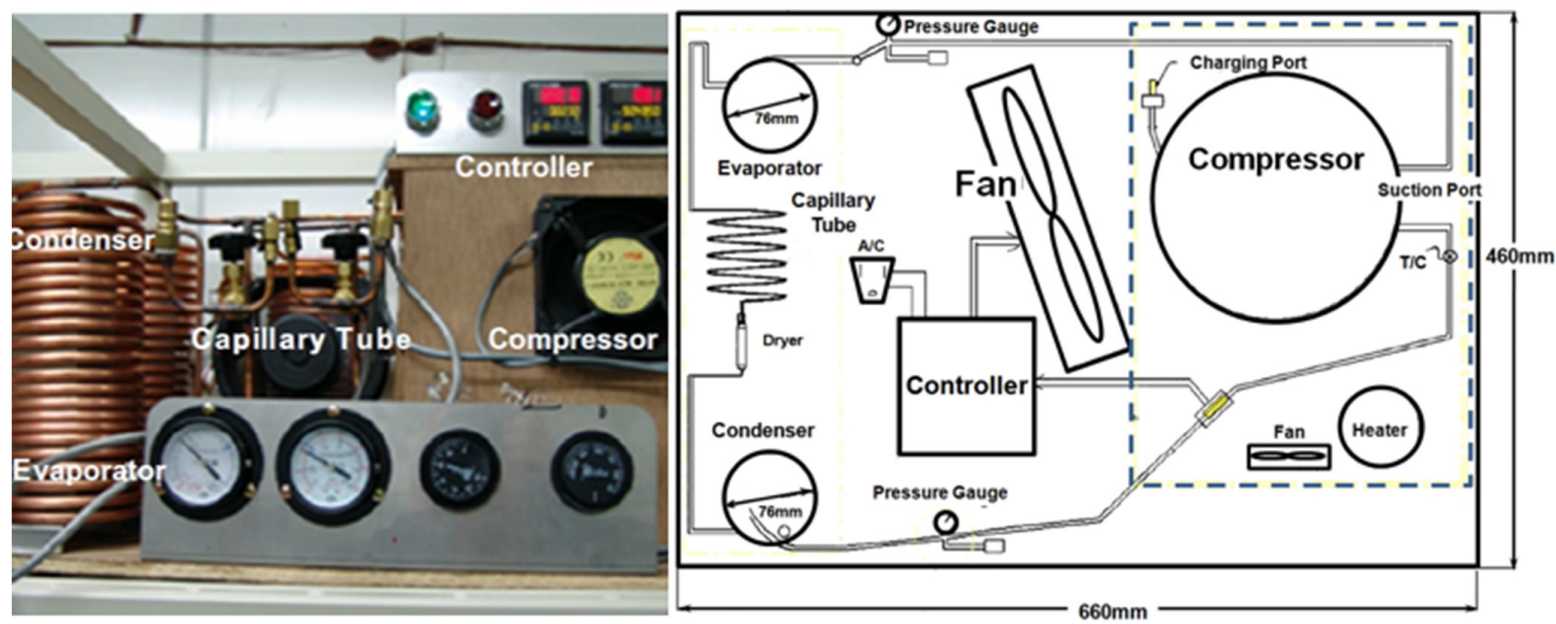

Figure 9. Equipment for the ALTs. 


\section{Results and Discussion}

A sample in the first ALT $(n=100)$ locked at 3500 cycles. Another sample continued working but had a partially broken suction reed at 7500 cycles (Figure 10). The shape parameter, $\beta$, formed from the first ALT, was 2.0 (see Figure 11). The forms and positions of the failure in the samples obtained from the first ALT and the field were alike (Figure 10). The fractured suction reed valve originated from three design faults: (1) it had a quantity of overlap with the valve plate, (2) it had a sharp edge on the valve plate, and (3) it used an insufficiently strong material (see Figures 6 and 12).

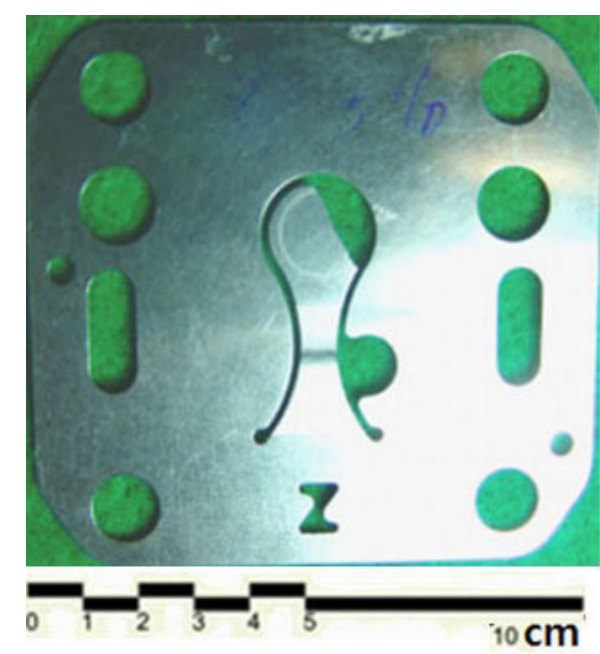

(a)

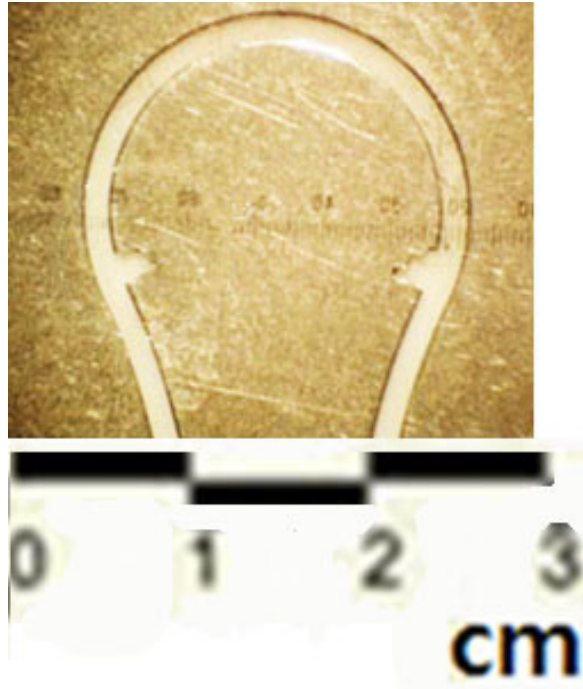

(c)

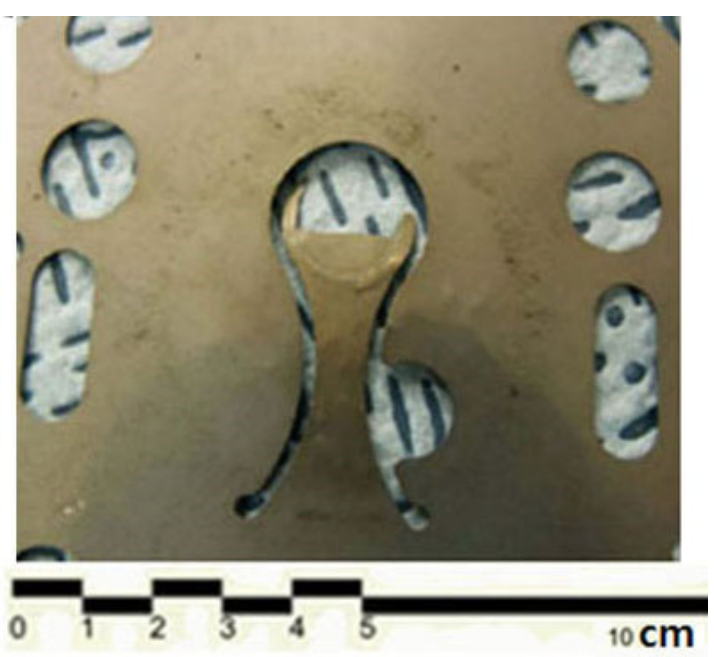

(b)

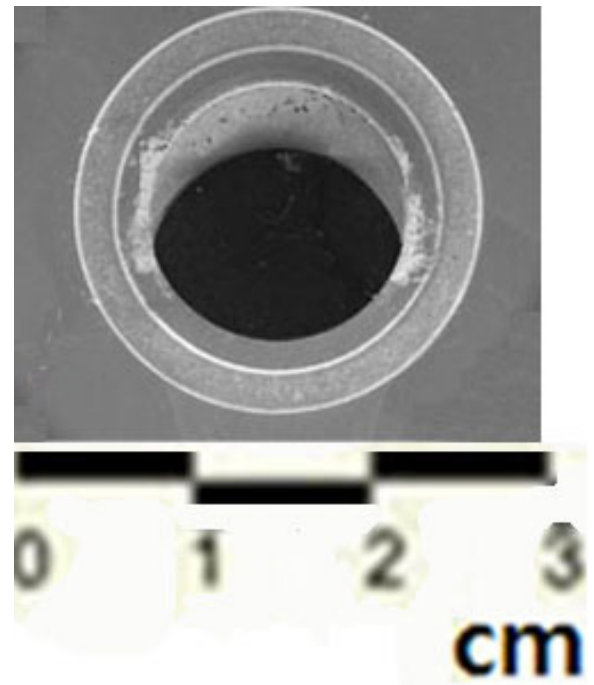

(d)

Figure 10. Failed suction reed valves from the field and first ALT: (a) failed products from the field, (b) outcome after first parametric ALT, (c) partially broken suction reed valve from the first ALT, (d) shattered valve plate. 


\section{Unreliability, F(t)}

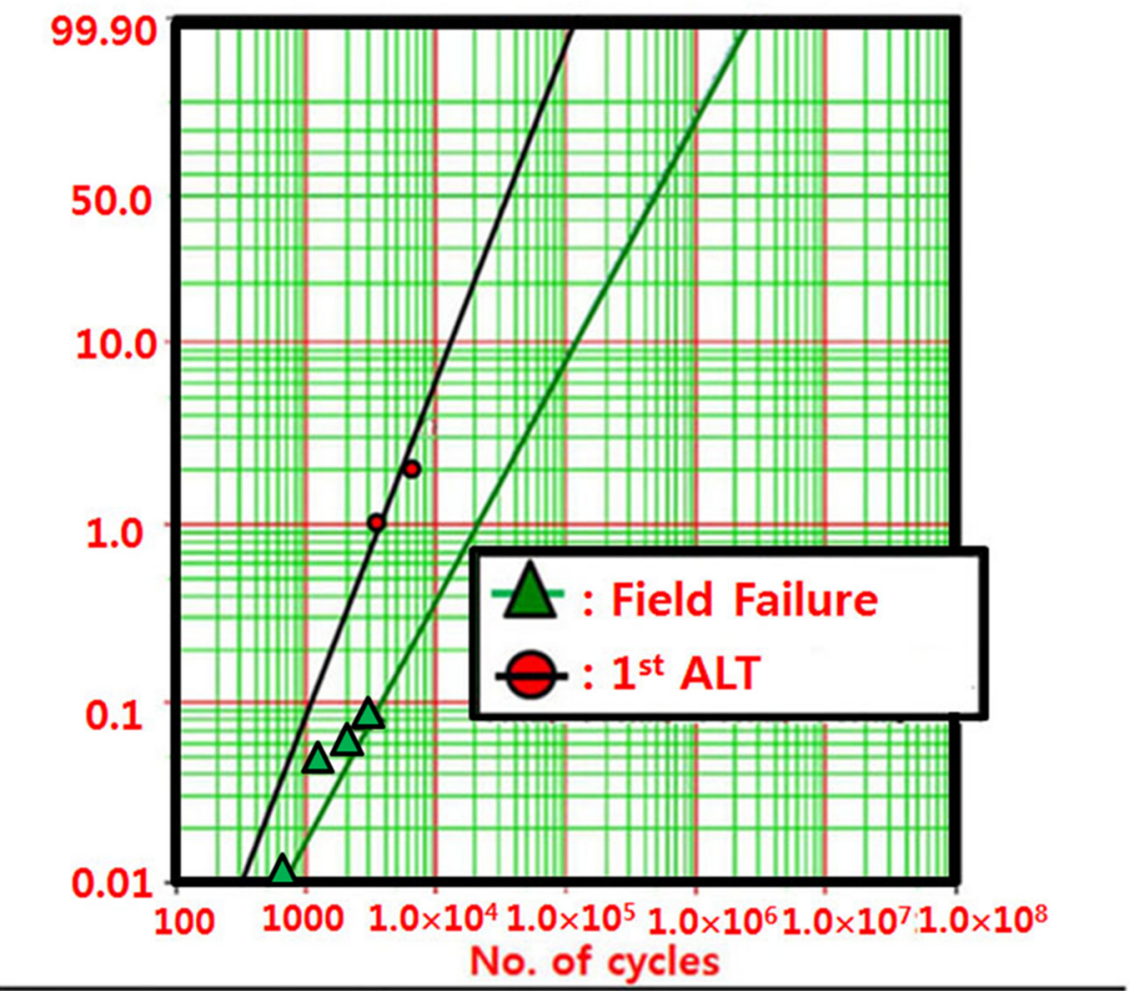

$\beta 1=1.95, \eta=4.3 \times 10^{4}$

$\beta 2=1.35, \eta=6.0 \times 10^{5}$

Figure 11. Market statistics and consequences of ALT on Weibull chart.

When the suction reed valve frequently striked the valve plate, it eventually fractured before its expected lifetime. The main failure mode of the compressor was locking due to the failed suction reed valve. The ALT methodology was well-suited for recognizing the fatigue failure attained from the units in the field. First, the shape of the failed suction reed valves from the marketplace and those in the first ALT were very similar in appearance.

The first ALT failure and market failure data manifested a similar pattern on a Weibull plot (Figure 11). As the data for the two models had similar gradients on the plot, each loading condition of the first ALT and that from the field over the product lifetime were similar. Therefore, it might be anticipated that the test samples in the laboratory would break in a similar way to those in the field. For the shape parameter, $\beta$, the last shape parameter from the chart was confirmed to be 2.0, compared with the approximated value2.0. Based on both test outcomes in the Weibull plot, the parametric ALT was successful because it recognized the design defects which were responsible for the market failures. In other words, as proven by two things-the visual likeness in both photos and similar slopes in the Weibull plot-these ALTs were justified in recognizing the design flaws that were judged as the failures from the market. These failures determined the product lifetime. 


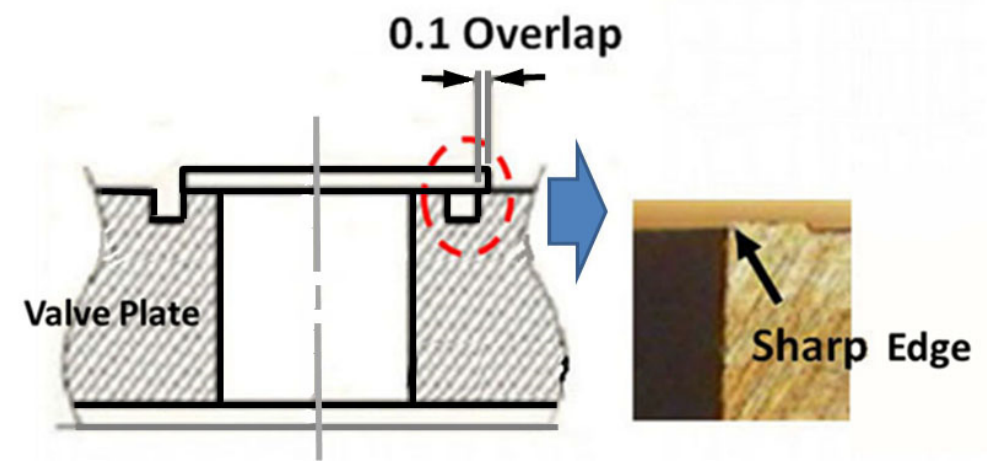

(a)

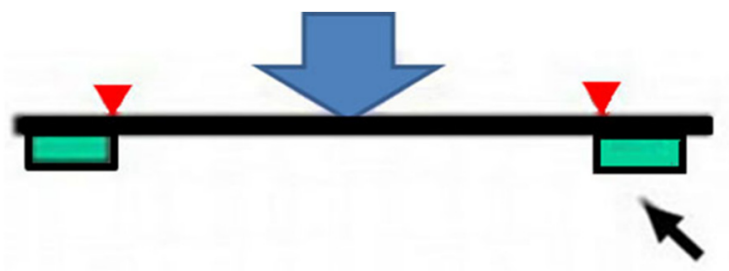

\section{Port}

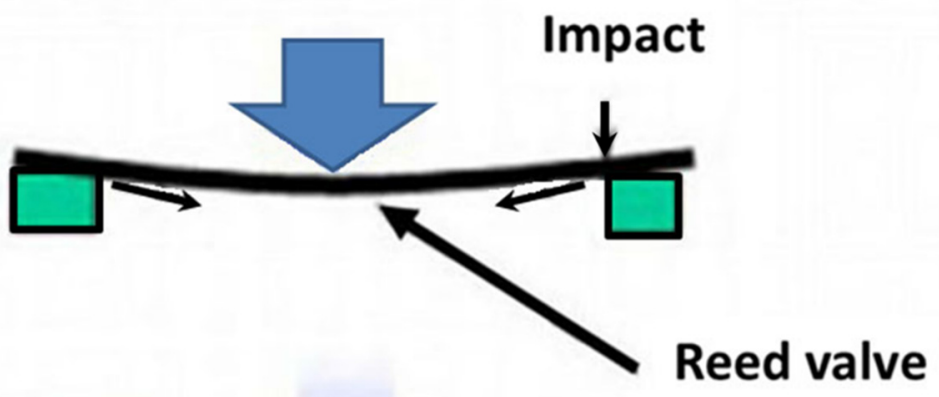

(b)

Figure 12. Structural design defects of suction reed and valve plate in a compressor: (a) overlapped suction reed valve and valve plate with sharp edge; (b) impact load in combination of design defects when compressor is worked.

Refrigerators that came from the field had a primary failure mode with no cooling because the compressor did not function. Field data suggested that the troublesome compressors may have had design flaws. Due to these defects, the repetitive pressure loads could produce unanticipated stresses on the suction reed valve, causing it to crack and propagate the crack to its end. To reproduce the dominant failure mode of the compressor, parametric ALTs were carried out. Based on the first ALT and market data, we realized that the $A F$ and $\beta$ values were 7.3 and 2.0 (see Figure 11). For assigned test samples, the test cycles were computed in Equation (12) if the product lifetime was secured to have a B1 life of 10 years.

To investigate a compressor that failed at 3500 cycles in the first ALT, the troublesome compressors came from the marketplace and the first ALT were compared to determine the potential design defects. The mode of the compressor failure in the first ALT was very similar to the ones from the field. The suction reed valves failed in areas where they were partly covered by the valve plate. The tests stated that the compressor was improperly designed to operate with this suction reed valve.

The failed suction reed valve originated from the unsuitable design flaws: (1) an quantity of overlap with the valve plate; (2) a sharp edge on the valve plate; and (3) 
insufficiently strong material $(0.178 \mathrm{t})$ utilized in the design of suction reed valve. These defects might cause the compressor system to fracture abruptly when subjected to repetitive pressure loads (see Figures 7 and 12).

To fix the failed suction reed valve failure that was due to the repetitive pressure stresses in the compressor's lifetime, the valve plate and suction reed valve was modified as follows: (1) trespan size from $0.73 \mathrm{~mm}$ to $1.25 \mathrm{~mm}$; (2) adding ball peening and brush process (see Figure 13); (3) thickening the suction reed valve from $0.178 \mathrm{t}$ to $0.203 \mathrm{t}$ (4) expanding tumbling process.

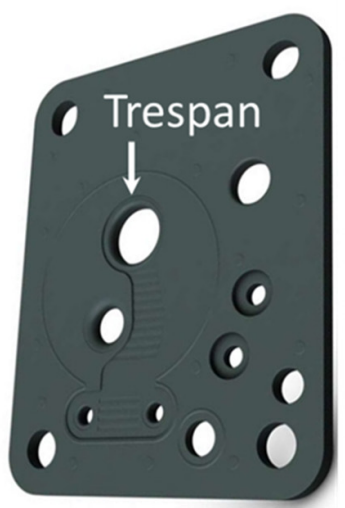

(a)
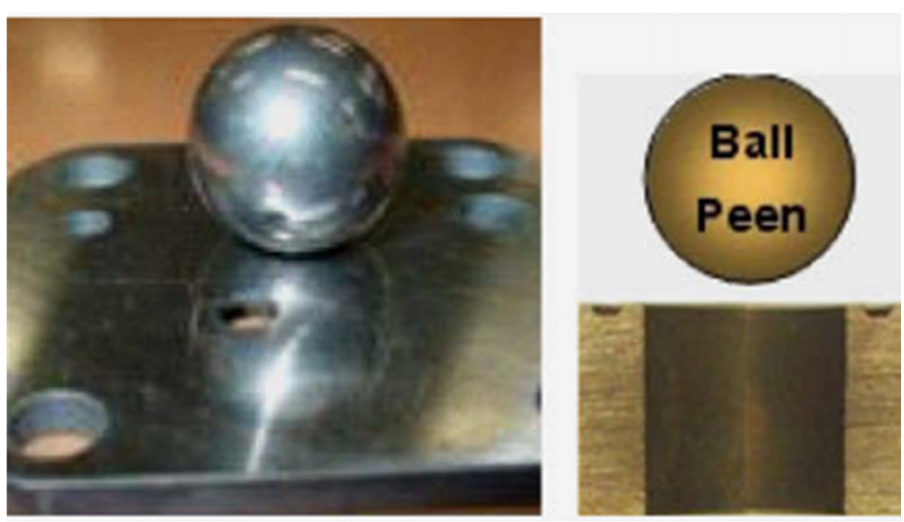

(b)

Figure 13. Redesigned valve plate: (a) trespan in valve plate; (b) ball peening process.

For the second ALT, three samples locked near 17,000 cycles. The problematic compressor system came as follows: (1) erosion of the crankshaft and (2) the intrusion between crank shaft and thrust washer. The design modification was provided to the heat treatment on the surface of crank shaft that can modify the physical, and sometimes chemical, properties of a material to achieve the desired result, such as hardening of a weak crankshaft material (Ductile Iron FCD500 - C $\geq 2.5 \mathrm{wt} \%, \mathrm{~S} \leq 0.02 \mathrm{wt} \%, \mathrm{Mg} \leq 0.09 \mathrm{wt} \%$ ).

In the third ALT, there were no design problems in the compressor until the parametric ALT was carried out to 49,000 cycles. We therefore concluded that the design modifications attained from the first and second ALTs were effective. Table 4 summarizes the parametric ALT results. With the modified design parameters, the compressor samples were ensured to attain the lifetime target-B1 life of 10 years with about a $60 \%$ confidence level.

Table 4. Compressor ALT outcomes.

\begin{tabular}{|c|c|c|c|}
\hline \multirow{2}{*}{ Parametric ALT } & First ALT & Second ALT & Third ALT \\
\hline & Original Design & Design & Final Design \\
\hline $\begin{array}{l}\text { In } 49,000 \text { cycles, there are no } \\
\text { issues in the compressor }\end{array}$ & $\begin{array}{c}3500 \text { cycles: } 1 / 100 \text { locking } \\
7500 \text { cycles: } 1 / 100 \text { broken suction reed valve }\end{array}$ & 17,000 cycles: 3/100 locking & 49,000 cycles: 100/100 OK \\
\hline \multicolumn{4}{|l|}{ Structure } \\
\hline Action plans & $\begin{array}{c}\text { C1: Trepan size: } \\
0.73 \mathrm{~mm} \rightarrow 1.25 \mathrm{~mm} \\
\text { C2: attaching ball peening and brush process } \\
\text { C3: SANDVIK 20C: } \\
0.178 \mathrm{t} \rightarrow 0.203 \mathrm{t} \\
\text { C4: expanding tumbling: } \\
4 \mathrm{~h} \rightarrow 14 \mathrm{~h}\end{array}$ & $\begin{array}{l}\text { C5: FCD500 + no heat } \\
\text { treatment } \rightarrow \text { FCD500 + heat } \\
\text { treatment on the crankshaft }\end{array}$ & \\
\hline
\end{tabular}




\section{Conclusions}

To increase the lifespan of a new domestic compressor in a refrigerator, the following reliability methodology was developed: (1) the system BX lifetime created the total parametric ALT scheme, (2) the parametric ALT with design modifications, and (3) determine if the product design attains the mission cycles. To show the effectiveness of this methodology for identifying and altering the design defects of a mechanical product, we derived the sample size equation, time-to-failure equation and acceleration method, and BX lifetime. As a test case, we inspected the redesign of a compressor that came from the marketplace.

- In the marketplace and the first ALT, we found that the failed suction reed valve in a compressor originated from the following design flaws: (1) a small overlap between the valve with the valve plate, (2) a sharp edge on the valve plate, and (3) inadequate width of the suction reed valve (SANDVIK20 C0.178t). As design modifications, the trepan on the valve plate was extended from $0.73 \mathrm{~mm}$ to $1.25 \mathrm{~mm}$, and a ball peening technique was secured to eliminate the sharp edge. For the second ALT, we found that three samples failed near 17,000 cycles because of the intrusion between the crankshaft and thrust washer. As an action plan, the crankshaft was heat-treated.

- During the third ALT, no problems were found. The compressor systems should attain the lifetime target-B1 life of 10 years with about a $60 \%$ confidence level.

- By examining problematic products returned from the marketplace and performing parametric ALTs with design modifications, it was possible to improve the expected lifetime of the compressor.

This reliability methodology can be applied to other mechanical products such as airplane, automobiles, and construction machines. To use this methodology, designers should understand why products fail during their lifetime. That is to say, if there are design flaws in the structure that are subjected to repetitive loads, the system will fail before its expected lifetime. Engineers would need to identify the load characteristics of a mechanical system so that the parametric ALT can be carried out until the required mission cycles under accelerated stress conditions. Finally, engineers can use parametric ALT to identify and alter the design problems of a mechanical product.

Author Contributions: S.W. managed the concept forming, methodology, examination and testing, and wrote the manuscript. D.L.O. examined the analysis and writing for the original manuscript and edited it. All authors have read and agreed to the published version of the manuscript.

Funding: This research accepted no external finance.

Institutional Review Board Statement: Not applicable.

Informed Consent Statement: Not applicable.

Data Availability Statement: The data provided in this research can be obtained on request from the corresponding author.

Conflicts of Interest: The authors express no conflict of interest.

\section{Abbreviations}

$A$

$B X$

$E_{a}$

$e$

$f$

$F(t)$

$F(t)$

$h$

$h^{*}$

J

\author{
Cross-sectional area of the capillary tube: $\mathrm{cm}^{2}$ \\ Time which is a cumulated failure rate of $X \%$ : durability index \\ Activation energy, $\mathrm{eV}$ \\ Effort \\ Flow \\ Impact force, $k N$ \\ Unreliability \\ Testing cycles (or cycles) \\ Non-dimensional testing cycles, $h^{*}=h / L_{B} \geq 1$ \\ Junction function equation
}




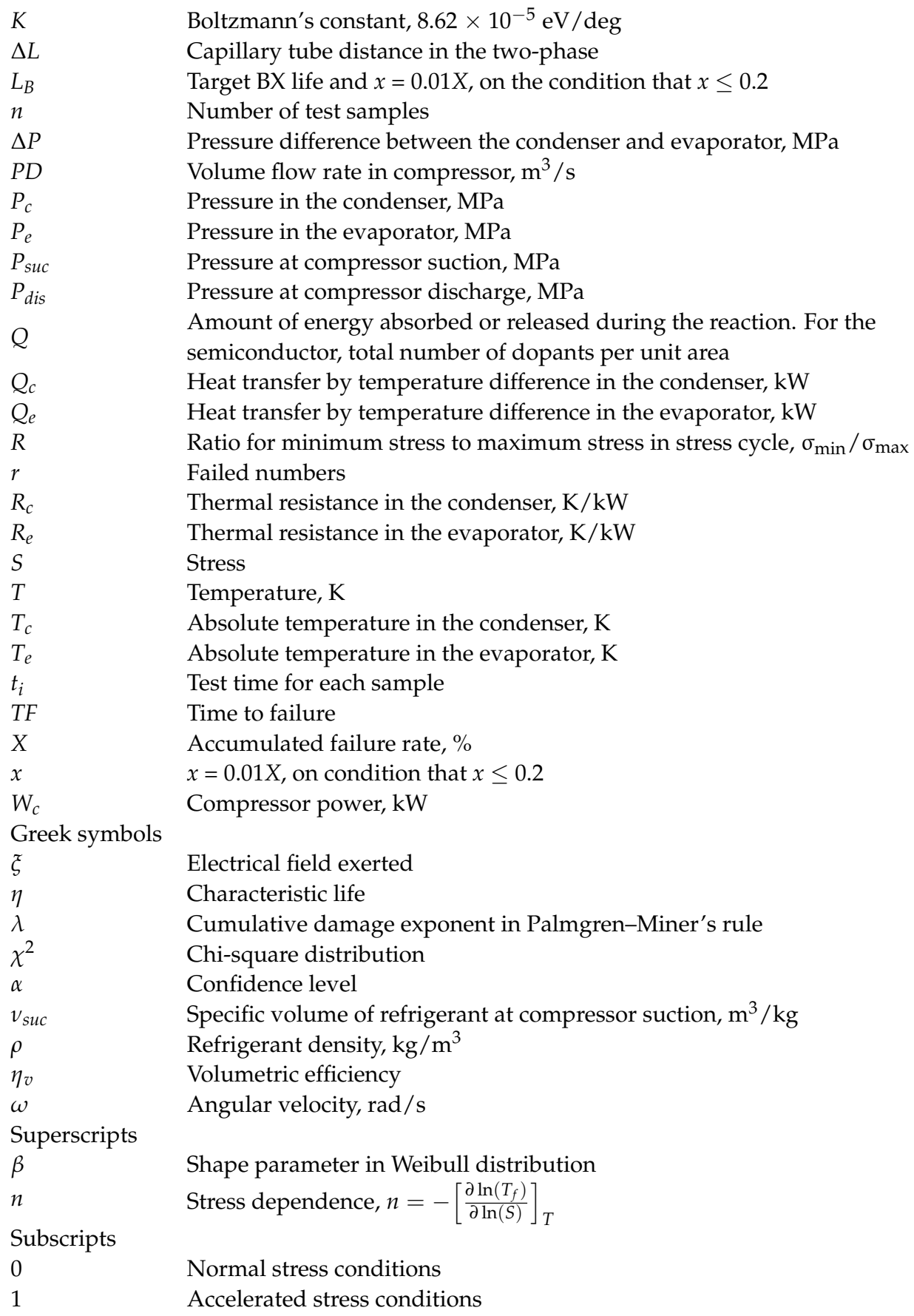

\section{Appendix A. Derivation of Sample Size Equation for Parametric ALT}

Presently, many methods have been proposed to resolve issues on sample size. The Weibayes model by using Weibull examination is a widely acknowledged method of inspecting reliability data. However, it is hard to be straightly used due to the complexity of the mathematical formulation. The entire instances as failures $(r \geq 1)$ and no failures $(r=0)$ need to be split. As a result, it is feasible to attain a predictable sample size equation which might supply the mission cycle after correct presumptions.

In selecting the model parameters to maximize the likelihood function, the maximum likelihood estimation (MLE) statistic is a general way of approximating the parameters of a model. The characteristic life $\eta_{M L E}$ would be stated as:

$$
\eta_{M L E}^{\beta}=\sum_{i=1}^{n} \frac{t_{i}^{\beta}}{r}
$$


where $\eta_{M L E}$ is the maximum likelihood estimate for the characteristic life, $n$ is the entire number of samples, $t_{i}$ is the experimental time for each sample, and $r$ is the number of failures.

If the failure numbers, $r$, greater than or equal to 1 and the confidence level is $100(1-\alpha)$, then the characteristic life, $\eta_{\alpha}$, can be estimated from Equation (A1).

$$
\eta_{\alpha}^{\beta}=\frac{2 r}{\chi_{\alpha}^{2}(2 r+2)} \times \eta_{M L E}^{\beta}=\frac{2}{\chi_{\alpha}^{2}(2 r+2)} \times \sum_{i=1}^{n} t_{i}^{\beta} \text { for } r \geq 1
$$

where $\chi_{\alpha}^{2}()$ is the chi-square distribution when the $p$-value is $\alpha$.

Presuming there are no failure numbers, $\ln (1 / \alpha)$ is similar to the chi-square value, $\frac{\chi_{\alpha}^{2}(2)}{2}[35]$.

$$
p-\text { value }: \alpha=\int_{\chi_{\alpha}^{2}(2)}^{\alpha}\left(\frac{e^{-\frac{x}{2}} x^{\frac{v}{2}-1}}{2^{\frac{v}{2}} \Gamma\left(\frac{v}{2}\right)}\right) d x=\int_{2 \ln \alpha^{-1}}^{\alpha}\left(\frac{e^{-\frac{x}{2}} x^{\frac{v}{2}-1}}{2^{\frac{v}{2}} \Gamma\left(\frac{v}{2}\right)}\right) d x \text { for } x \geq 0
$$

where $v$ is the shape parameter and $\Gamma$ is the gamma function.

For $r=0$, the characteristic life $\eta_{\alpha}$ from Equation (A2) might be stated as:

$$
\eta_{\alpha}^{\beta}=\frac{2}{\chi_{\alpha}^{2}(2)} \times \sum_{i=1}^{n} t_{i}^{\beta}=\frac{1}{\ln \frac{1}{\alpha}} \times \sum_{i=1}^{n} t_{i}^{\beta}
$$

As Equation (A2) is demonstrated for all cases $r \geq 0$, characteristic life, $\eta_{\alpha}$, might be stated as:

$$
\eta_{\alpha}^{\beta}=\frac{2}{\chi_{\alpha}^{2}(2 r+2)} \times \sum_{i=1}^{n} t_{i}^{\beta} \text { for } r \geq 0
$$

If the logarithm in the Weibull distribution is used, the relationship between characteristic life and $\mathrm{BX}$ life, $L_{B}$, might be stated as:

$$
L_{B}^{\beta}=\left(\ln \frac{1}{1-x}\right) \times \eta_{\alpha}^{\beta}
$$

If the estimated characteristic life of the $p$-value $\alpha, \eta_{\alpha}$, in Equation (A5), is substituted into Equation (A6), we obtain the BX life equation:

$$
L_{B}^{\beta}=\left(\ln \frac{1}{1-x}\right) \times \frac{2}{\chi_{\alpha}^{2}(2 r+2)} \times \sum_{i=1}^{n} t_{i}^{\beta}
$$

As whole reliability testing has insufficient sample numbers to assess the lifetime for the designated failures, which might be less than that of the sample size, the experiment plan can be stated as:

$$
n h^{\beta} \geq \sum t_{i}^{\beta} \geq(n-r) \times h^{\beta}
$$

If Equation (A8) is changed with Equation (A7), the BX life equation might be restated as:

$$
L_{B}^{\beta} \cong\left(\ln \frac{1}{1-x}\right) \times \frac{2}{\chi_{\alpha}^{2}(2 r+2)} \cdot n h^{\beta} \geq\left(\ln \frac{1}{1-x}\right) \times \frac{2}{\chi_{\alpha}^{2}(2 r+2)} \times(n-r) h^{\beta} \geq L_{B}^{* \beta}
$$

If Equation (A9) is reorganized, the sample size equation with the failures can be stated as:

$$
n \geq \frac{\chi_{\alpha}^{2}(2 r+2)}{2} \times \frac{1}{\left(\ln \frac{1}{1-x}\right)} \times\left(\frac{L_{B}^{*}}{h}\right)^{\beta}+r
$$


Because $\frac{\chi_{\alpha}^{2}(2 r+2)}{2} \cong(r+1)$ for $\alpha=0.6$ and $\ln (1-x)^{-1}=x+\frac{x^{2}}{2}+\frac{x^{3}}{3}+\ldots \cong x$, the sample size Equation (A10) can be straightforwardly adjacent to:

$$
n \geq(r+1) \times \frac{1}{x} \times\left(\frac{L_{B}^{*}}{h}\right)^{\beta}+r
$$

where the sample size equation can be stated as $n \sim($ failure numbers +1$) \cdot(1 /$ cumulative failure rate $) \cdot((\text { target lifetime }) /(\text { plan testing time }))^{\wedge} \beta+r$.

\section{References}

1. Woo, S.; O'Neal, D.; Woldemichael, D.E.; Atnaw, S.M.; Tulu, M.M. Improving the Fatigue of Newly Designed Mechanical System Subjected to Repeated Impact Loading. Metals 2021, 11, 139. [CrossRef]

2. CMMI Product Team. Capability Maturity Model Integration (CMMI) Version 2.0, Continuous Representation; Report CMU/SEI-2002TR-011; Software Engineering Institute: Pittsburgh, PA, USA, 2018.

3. Magaziner, I.C.; Patinkin, M. Cold competition: GE wages the refrigerator war. Harv. Bus. Rev. 1989, 89, $114-124$.

4. Rosa, J.L.; Robin, A.; Silva, M.B.; Baldan, C.A.; Peres, M.P. Electrodeposition of copper on titanium wires: Taguchi experimental design approach. J. Mater. Process. Technol. 2009, 209, 1181-1188. [CrossRef]

5. Chowdhury, S.; Taguchi, S. Robust Optimization: World's Best Practices for Developing Winning Vehicles, 1st ed.; John Wiley \& Sons Inc.: Hoboken, NJ, USA, 2016.

6. Allen, P. Design of Experiments for 21st Century Engineers, 1st ed.; Lulu Press: Morrisville, NC, USA, 2020.

7. Duga, J.J.; Fisher, W.H.; Buxaum, R.W.; Rosenfield, A.R.; Buhr, A.R.; Honton, E.J.; McMillan, S.C. The Economic Effects of Fracture in the United States; Final Report; Available as NBS Special Publication 647-2; Battelle Laboratories: Columbus, OH, USA, 30 September 1982.

8. Toribio, J.; Kharin, V.; Ayaso, F.J; González, B.; Matos, J.C.; Vergara, D.; Lorenzoc, M. Failure analysis of a lifting platform for tree pruning. Eng. Fail. Anal. 2010, 17, 739-747. [CrossRef]

9. Akama, M. Fatigue Crack Growth under Non-Proportional Mixed Mode Loading in Rail and Wheel Steel Part 1: Sequential Mode I and Mode II Loading. Appl. Sci. 2019, 9, 2866. [CrossRef]

10. Fatigue. In Elements of Metallurgy and Engineering Alloys; Campbell, F.C. (Ed.) ASM International: Materials Park, OH, USA, 2008.

11. Modarres, M.; Kaminskiy, M.; Krivtsov, V. Reliability Engineering and Risk Analysis: A Practical Guide, 3rd ed.; CRC Press: Boca Raton, FL, USA, 2016.

12. Elsayed, E.A. Reliability Engineering; John Wiley \& Sons: Hoboken, NJ, USA, 2012.

13. Hahn, G.J.; Meeker, W.Q. How to Plan an Accelerated Life Test (E-Book); ASQ Quality Press: Milwaukee, WI, USA, 2004.

14. McPherson, J. Accelerated testing. In Electronic Materials Handbook Volume 1: Packaging; ASM International Publishing: Materials Park, OH, USA, 1989; pp. 887-894.

15. McPherson, J. Reliability Physics and Engineering: Time-to-Failure Modeling; Springer: New York, NY, USA, 2010.

16. Griffith, A.A. The phenomena of rupture and flow in solids. Philos. Trans. R Soc. Lond. A 1921, 221, 163-198.

17. Irwin, G. Analysis of stresses and strains near the end of a crack traversing a plate. J. Appl. Mech. 1957, 24, 361-364. [CrossRef]

18. Anderson, T.L. Fracture Mechanics_Fundamentals and Applications, 3rd ed.; CRC: Boca Raton, FL, USA, 2017.

19. ASTM E606/E606M. Standard Test Method for Strain-Controlled Fatigue Testing; ASTM International: West Conshohocken, PA, USA, 2019.

20. ASTM E399. Standard Test Method for Linear-Elastic Plane-Strain Fracture Toughness of Metallic Materials; ASTM International: West Conshohocken, PA, USA, 2020.

21. ASTM E647. Standard Test Method for Measurement of Fatigue Crack Growth Rates; ASTM International: West Conshohocken, PA, USA, 2015.

22. ASTM E739-10. Standard Practice for Statistical Analysis of Linear or Linearized Stress-Life (S-N) and Strain-Life ( $\varepsilon-N)$ Fatigue Data; ASTM International: West Conshohocken, PA, USA, 2015.

23. Braco, R.; Prates, P.; Costa, J.D.M.; Berto, F. New methodology of fatigue life evaluation for multiaxially loaded notched components based on two uniaxial strain-controlled tests. Int. J. Fatigue 2018, 111, 308-320. [CrossRef]

24. Weingart, R.G.; Stephen, P. Timoshenko: Father of Engineering Mechanics in the U.S. Structure Magazine, August 2007.

25. Sánchez, M.; Cicero, S.; Arroyo, B.; Álvarez, J.A. Coupling Finite Element Analysis and the Theory of Critical Distances to Estimate Critical Loads in Al6060-T66 Tubular Beams Containing Notches. Metals 2020, 10, 1395. [CrossRef]

26. Li, Q.; Xie, L. Analysis and Optimization of Tooth Surface Contact Stress of Gears with Tooth Profile Deviations, Meshing Errors and Lead Crowning Modifications Based on Finite Element Method and Taguchi Method. Metals 2020, 10, 1370. [CrossRef]

27. Hertzberg, R.W.; Vinci, R.P.; Hertzberg, J.L. Deformation and Fracture Mechanics of Engineering Materials, 6th ed.; John Wiley and Sons Inc.: Hoboken, NJ, USA, 2020.

28. Zupančič, B.; Prokop, Y.; Nikonov, A. FEM analysis of dispersive elastic waves in three-layered composite plates with high contrast properties. Finite Elem. Anal. Des. 2021, 193, 103553. [CrossRef] 
29. IEEE Standard Glossary of Software Engineering Terminology. IEEE STD 610.12-1990. Standards Coordinating Committee of the Computer Society of IEEE. (reaffirmed September 2002). Available online: https://ieeexplore.ieee.org/document/159342 (accessed on 31 December 2020).

30. Kreyszig, E. Advanced Engineering Mathematics, 10th ed.; John Wiley and Son: Hoboken, NJ, USA, 2011 ; p. 683.

31. Grove, A. Physics and Technology of Semiconductor Device, 1st ed.; Wiley International Edition: New York, NY, USA, $1967 ;$ p. 37.

32. Minges, M.L. Electronic Materials Handbook; ASM International: Cleveland, OH, USA, 1989; Volume 1, p. 888.

33. Karnopp, D.C.; Margolis, D.L.; Rosenberg, R.C. System Dynamics: Modeling, Simulation, and Control of Mechatronic Systems, 6th ed.; John Wiley \& Sons: New York, NY, USA, 2012.

34. Whitesel, H.A. Capillary two-phase flow Part II. Refrig. Eng. 1957, 65, 35-40.

35. Abernethy, R.B. The New Weibull Handbook; Reliability Analysis Center: North Palm Beach, FL, USA, $2000 ;$ pp. 1-310. 